\title{
Hyperlipidemic microenvironment conditionates damage mechanisms in human chondrocytes by oxidative stress
}

\author{
Daniel Medina-Luna ${ }^{1 \dagger}$, Mónica Guadalupe Santamaría-Olmedo ${ }^{1 \dagger}$, Yessica Zamudio-Cuevas ${ }^{1}$, \\ Karina Martínez-Flores ${ }^{1}$, Javier Fernández-Torres ${ }^{1,2}$, Gabriela Angélica Martínez-Nava ${ }^{1}$, Denise Clavijo-Cornejo ${ }^{1}$, \\ Cristina Hernández-Díaz $z^{3}$, Anell Olivos-Meza ${ }^{4}$, Luis Enrique Gomez-Quiroz², María Concepción Gutiérrez-Ruiz², \\ Carlos Pineda ${ }^{3}$, Francisco Blanco ${ }^{5}$, Anthony M. Reginato ${ }^{6}$ and Alberto López-Reyes ${ }^{1 *}$ (D)
}

\begin{abstract}
Background: Currently, two pathogenic pathways describe the role of obesity in osteoarthritis (OA); one through biomechanical stress, and the other by the contribution of systemic inflammation. The aim of this study was to evaluate the effect of free fatty acids (FFA) in human chondrocytes $(\mathrm{HC})$ expression of proinflammatory factors and reactive oxygen species (ROS).

Methods: $\mathrm{HC}$ were exposed to two different concentrations of FFA in order to evaluate the secretion of adipokines through cytokines immunoassays panel, quantify the protein secretion of FFA-treated chondrocytes, and fluorescent cytometry assays were performed to evaluate the reactive oxygen species (ROS) production.
\end{abstract}

Results: $\mathrm{HC}$ injury was observed at $48 \mathrm{~h}$ of treatment with FFA. In the FFA-treated HC the production of reactive oxygen species such as superoxide radical, hydrogen peroxide, and the reactive nitrogen species increased significantly in a at the two-dose tested (250 and $500 \mu \mathrm{M}$ ). In addition, we found an increase in the cytokine secretion of IL-6 and chemokine IL-8 in FFA-treated HC in comparison to the untreated HC.

Conclusion: In our in vitro model of HC, a hyperlipidemia microenvironment induces an oxidative stress state that enhances the inflammatory process mediated by adipokines secretion in HC.

Keywords: Chondrocytes, Free fatty acids, Inflammation, Oxidative stress

\section{Background}

Osteoarthritis (OA) is a degenerative disease characterized by alterations in the cartilage, synovial membrane and subchondral bone that trigger the progressive and irreversible degeneration of the joint. OA is one of the most common musculoskeletal disorders of the aging population [1-3], and a leading cause of chronic disability. A great variety of risk factors contributes to the development of OA such as age, gender, joint trauma, genetic factors, excessive joint usage (such as physical

\footnotetext{
* Correspondence: allorey@yahoo.com

${ }^{\dagger}$ Equal contributors

'Synovial Fluid Laboratory, Instituto Nacional de Rehabilitación "Luis Guillermo Ibarra", Calzada México Xochimilco 289, 14389 Mexico City, Mexico Full list of author information is available at the end of the article
}

cartilage-overload) and particularly obesity $[4,5]$. Obesity is one of the most important risk factors for OA as the hyaline cartilage can be damaged in two different mechanisms: (1) biomechanical stress and (2) inflammatory systemic factors [6-8]. The first one is caused by an altered biomechanics (especially in the knee); whereas the second one is derived from a pro-inflammatory state regulated by the activation of adipocytes which are natural producers of adipokines: leptin, adiponectin, resistin and visfatin [9]. These proteins are systematically present, thus they are present also in the joint and could be involved in its degradation [4]; however, it is not clear if a highly lipidic microenvironment within the human cartilage may promote a similar response [10]. In OA patients, there are some proteins that play an important role in inflammation and degradation of the cartilage such 
as, metalloproteinase 9 (MMP9) and 13 (MMP 13), and cytokines such as interleukine-1 (IL-1), interleukine-8 (IL8 ), interleukine-6 (IL-6), and Interferon- $\gamma$ (IFN- $\gamma$ ). In addition, these molecules are also involved in the generation of nitric oxide (NO) and reactive oxygen species (ROS) such as superoxide anion $\left(\mathrm{O}_{2}^{-}\right)$and hydrogen peroxide $\left(\mathrm{H}_{2} \mathrm{O}_{2}\right)$ [11-13]. The importance of $\mathrm{ROS}$ in OA is that these molecules are implicated in intracellular oxidation, especially in lipid peroxidation, which promotes cell membrane damage, protein oxidation and eventually lead to chondrocyte apoptosis [14-16]. An increase in ROS production in the joint is common in OA, and it has previously been reported that an imbalance in the chondrocyte metabolism could be related to an increase in chondrocyte lipid content [17].

The deposition of free fatty acids (FFA) within the joint stimulates both a deregulation of the metabolic process and an imbalance of the oxygen available. To address this issue, we used an in vitro $\mathrm{HC}$ model where we used FFA intra-cartilage as inductors of oxidative and inflammatory state.

\section{Methods}

\section{Human articular chondrocytes}

Hyaline cartilage biopsies, macroscopically healthy and $4 \mathrm{~mm}$ in diameter, were harvested by arthroscopy from a non-weight bearing area of the knees (lateral wall of the notch), from four consecutive patients who underwent surgery for Anterior Cruciate Ligament (ACL) repair. Three of these patients were female whereas one was male, with an average age of $44.25 \pm 24.81$ years, and a mean body mass index of $26.97 \pm 5.33 \mathrm{~kg} / \mathrm{m}^{2}$. All participants were appropriately informed about the study aims and signed an informed consent form. This study meets all the criteria contained in the Declaration of Helsinki and was approved by the Ethics and Research Committee of the Instituto Nacional de Rehabilitación (INR) (Ref. INR-08/11).

\section{Primary isolation and culture of human chondrocytes}

Immediately after the harvesting process, the cartilage tissue was subjected to mechano-enzymatic breakdown in order to isolate the HC as previously described [18]. Cells were cultured in DMEM/F12 medium supplemented with $10 \%$ fetal bovine serum (FBS) and 1\% antibiotics (Gibco, Thermo-Fischer Scientific, Waltham, MA USA). Cell cultures were maintained at $37{ }^{\circ} \mathrm{C}$, with $5 \%$ of $\mathrm{CO}_{2}$, at saturation humidity. Chondrocytes from the fourth passage were used for all experiments, the $\mathrm{HC}$ were characterized using Western Blot analysis for SOX9 transcription factor to ensure the phenotype of the cells were maintained all along the study (Fig. 1).

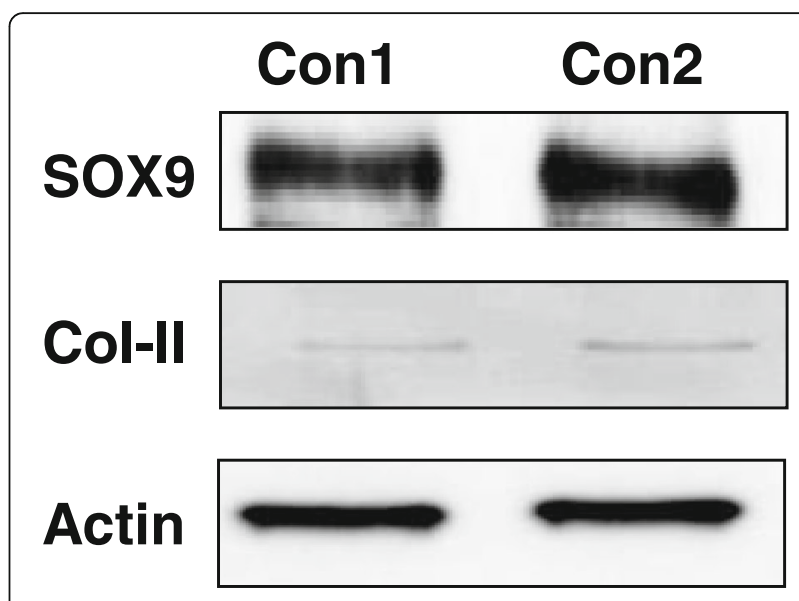

Fig. 1 Phenotypic characterization of human chondrocytes: Western blot analysis of the transcriptional factor SOX 9, Collagen type II, and actin expressed by human chondrocytes in monolayer culture

\section{Experimental design}

To assure statistical significance each experiment was performed in triplicate for all patients $(n=4)$. HC were treated with a FFA mixture composed of palmitic acid (C16), and oleic acid (C18:1, cis-9) (Sigma-Aldrich St. Louis, Missouri USA), in a ratio $1: 2$ respectively at concentrations of 250 and $500 \mu \mathrm{M}$ for $48 \mathrm{~h}$, respectively. As a positive control for oxidative stress, $100 \mu \mathrm{M}$ of $\mathrm{H}_{2} \mathrm{O}_{2}$ was used, and cells maintained under the same condition, while $\mathrm{HC}$ not exposed to FFA or $\mathrm{H}_{2} \mathrm{O}_{2}$ were used as a negative control. The lipid overload within the $\mathrm{HC}$ was confirmed by Oil red staining [19]. After the exposition to the FFA, the supernatant from cell cultures was collected and stored immediately at $-20{ }^{\circ} \mathrm{C}$, and cells were carefully harvested for the measurement of ROS and reactive nitrogen species (RNS).

\section{Oxidative stress measurement}

ROS and RNS production was evaluated through intracellular determination of $\mathrm{O}_{2}^{--}, \mathrm{H}_{2} \mathrm{O}_{2}$ and $\mathrm{NO}$ using the Tali Image-based Cytometer (Life Technologies). $\mathrm{O}_{2}^{--}$and $\mathrm{H}_{2} \mathrm{O}_{2}$ were quantified, by oxidation of the dihydroethidium (DHE) and the 5-, 6- carboxy-2', 2', 7'-dichlorofluorescein diacetate (carboxy- H2DCFDA) respectively (kit Image-iT LIVE Green Reactive Oxygen Species Detection). NO was detected using the commercial kit DAF-FM (4-amino5-methylamino-2,7-difluorofluorescein diacetate, Molecular Probes). DHE was quantified in the $530 \pm 20 \mathrm{~nm}$ emission filter, and the carboxyH2DCFDA and DAF-FM fluorescence in the $458 \pm 20 \mathrm{~nm}$ emission filters, according to the manufacturer's instructions. 


\section{Pro-inflammatory proteins quantification in HC culture medium}

Pro-inflammatory cytokines were evaluated in the supernatant from FFA-untreated, FFA-treated, and $\mathrm{H}_{2} \mathrm{O}_{2}$ treated HC cells by Milliplex Human Adipocyte Magnetic Panel (Merck-Millipore, Darmstadt, Germany). The pro-inflammatory cytokine quantification was performed by Magpix Merck-Millipore and the results were expressed in $\mathrm{ng} / \mathrm{ml}$. The samples were analyzed by triplicate according to manufacturer's instructions.

\section{Statistical analysis}

Data are presented as mean \pm standard deviation (SD). Statistical differences between experimental groups were assessed by one-way ANOVA test adjusted by Bonferroni multiple-comparison test. The mean of the estimated difference in ROS intracellular production relative units, as well as in secreted proteins concentration between groups was assessed by linear regression models. To assess the association between ROS intracellular production and secreted protein concentrations, Spearman correlation coefficients were calculated with their respective $P$-values adjusted by Bonferroni test combining data from both FFA concentrations. All $P$-values lower than 0.05 were considered as statistically significant. Prism v6.01 (GraphPad Software Inc., California, USA) and STATA v12.1 (StataCorporation, College Station, TX, USA) were used to perform the analysis and graphs.

\section{Results}

\section{$\mathrm{HC}$ overload lipids under FFA treatment}

Treatment of $\mathrm{HC}$ with 250 or $500 \mu \mathrm{M}$ of FFA for $48 \mathrm{~h}$ lead to increase $\mathrm{HC}$ lipid overload by Oil red staining. Figure 2 shows that $\mathrm{HC}$ without FFA stimulation did not present significant lipid load (Fig. 2a); however, FFA-treatment, induced an overload of neutral lipids in exposed HC, suggesting an efficient cellular load at both FFA concentrations (Fig. 2b and c).

\section{FFA increase ROS and RNS production in HC}

$\mathrm{HC}$ treated with 250 and $500 \mu \mathrm{M}$ of FFA for $48 \mathrm{~h}$ increased the production of ROS and RNS. The intracellular content of $\mathrm{O}_{2}^{-}$increased to $14 \%$ in $\mathrm{HC}$ exposed to $250 \mu \mathrm{M}$ of FFA $(1.14 \pm 0.05$ vs $1.0, P<0.01)$ and $35 \%$ when exposed to $500 \mu \mathrm{M}$ of FFA $(1.35 \pm 0.02$ vs 1.0, $P<0.01$ ) compared to untreated HC (Fig. 3a). In addition, $\mathrm{HC}$ exposed to FFA showed an increase in $\mathrm{H}_{2} \mathrm{O}_{2}$ production of $17 \%$ when treated with $250 \mu \mathrm{M}$ of FFA $(1.17 \pm 0.04$ vs $1.0, P<0.01)$, and $30 \%$ when treated with $500 \mu \mathrm{M}(1.30 \pm 0.03$ vs $1.0, P<0.01)$, compared to untreated HC (Fig. 3b). Similarly, the NO production increased to $11 \%(1.11 \pm 0.02$ vs $1.0, P<0.01)$ and $24 \%$ (1.24 \pm 0.04 vs $1.0, P<0.01)$ in $\mathrm{HC}$ exposed to 250 and
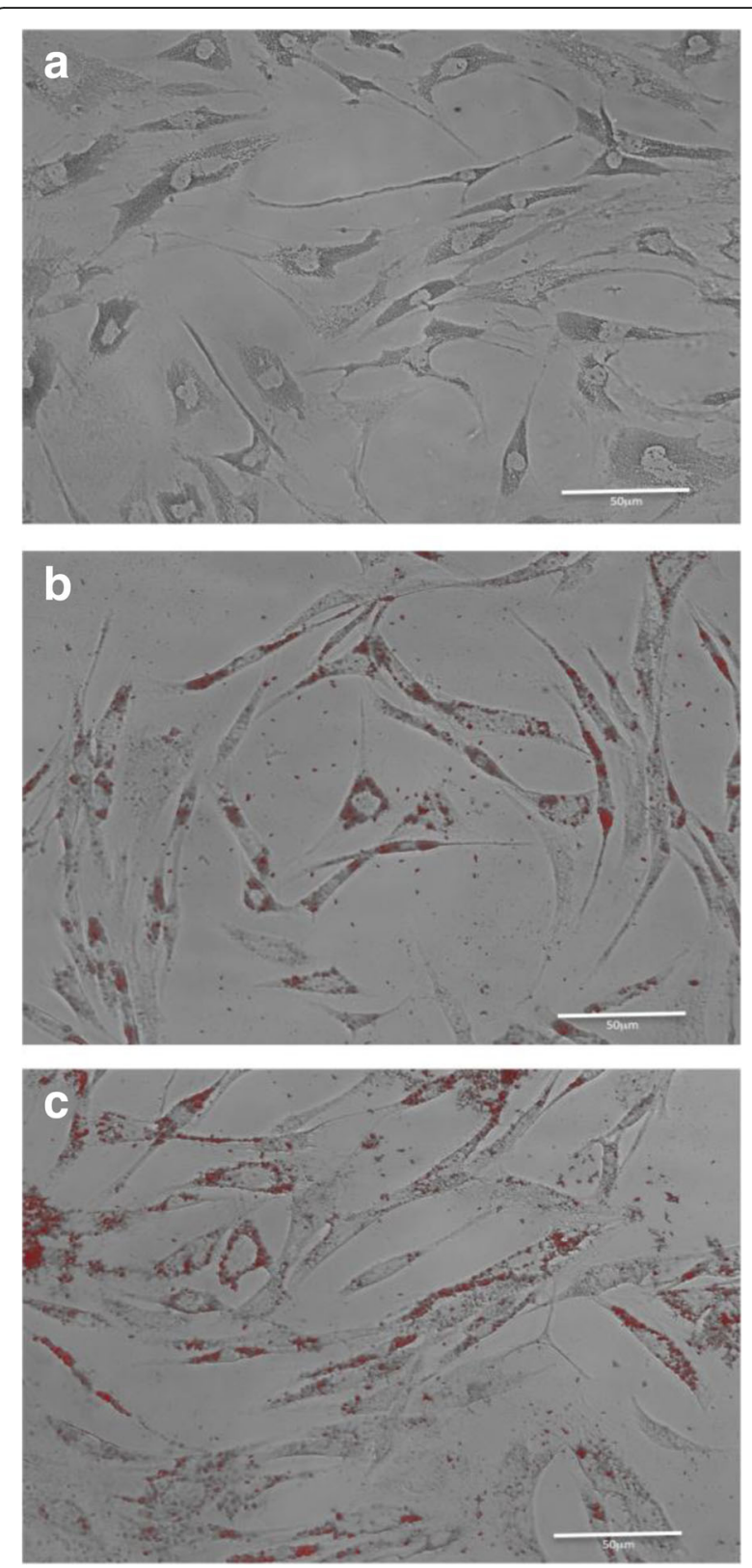

Fig. 2 Free Fatty Acid Internalization: Oil Red O Staining of human chondrocytes (HC) exposed to $250 \mu \mathrm{M}$ and $500 \mu \mathrm{M}$ FFA. Free fatty acids induce the increment in the lipid content in human chondrocytes (HC) a Not FFA- treated HC. b HC exposed to $250 \mu \mathrm{M}$ FFA and $\mathbf{c}$ HC exposed to $500 \mu \mathrm{M}$ FFA for 48 hs. Representative images of three different monolayer cultures

$500 \mu \mathrm{M}$ of FFA, respectively, compared to untreated HC. (Fig. 3b). Our positive $\mathrm{H}_{2} \mathrm{O}_{2}$ control showed an increase of $56 \%(1.56 \pm 0.05$ vs $1.0, P<0.01)$ in the $\mathrm{O}_{2}^{-}$ concentration, an increase of $34 \%(1.34 \pm 0.07$ vs 1.0, $P<0.01)$ in the $\mathrm{H}_{2} \mathrm{O}_{2}$ production and an increase of $35 \%(1.35 \pm 0.02$ vs $1.0, P<0.01)$ in the NO production. (Fig. 3a-c). 


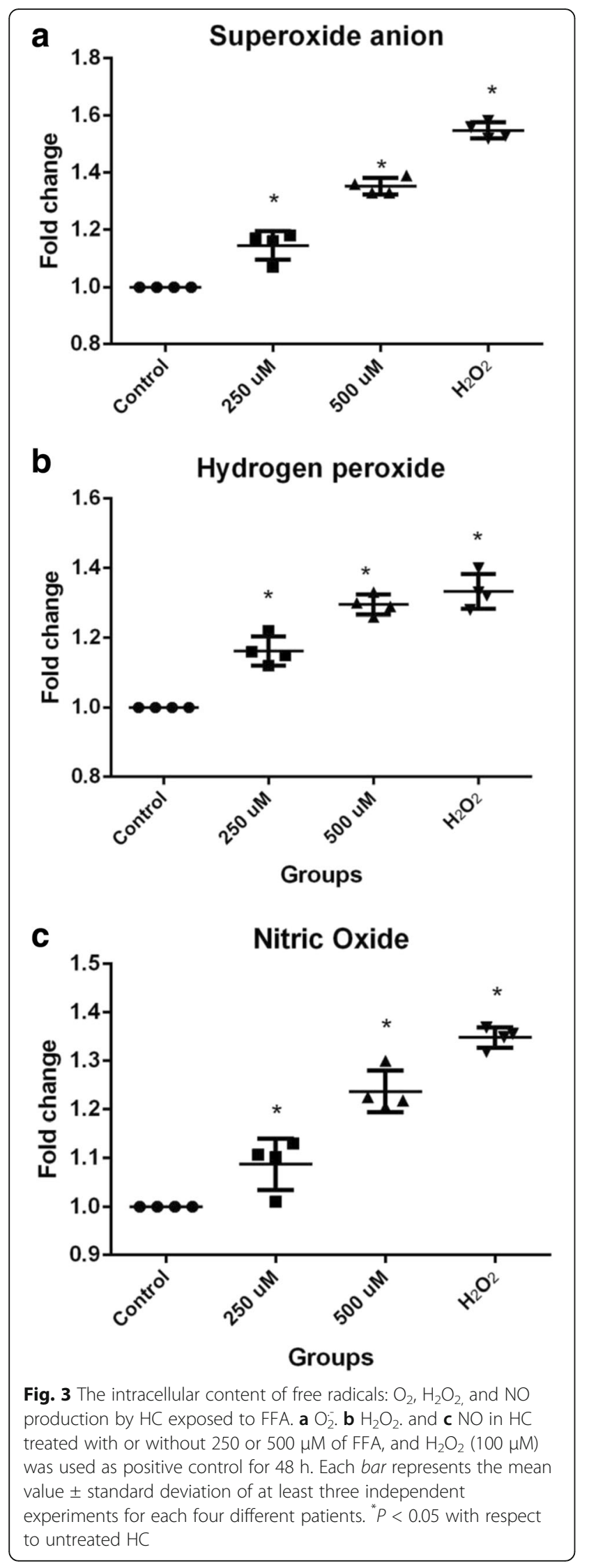

Free fatty acids induce pro-inflammatory secretion in HC In order to address the secretion of pro-inflammatory mediators elicited by lipid overload in $\mathrm{HC}$, we determined the concentration of IL-6, and IL- 8 in the supernatant of $\mathrm{HC}$ exposed to 250 and $500 \mu \mathrm{M}$ of FFA for $48 \mathrm{~h}$. IL-6 increased in a dose-dependent manner, having an average concentration of $21.7 \mathrm{ng} / \mathrm{ml}(P=0.02)$ and $26.3 \mathrm{ng} / \mathrm{ml}(P<0.01)$ with 250 and $500 \mu \mathrm{M}$ FFA, respectively in comparison to $18.5 \mathrm{ng} / \mathrm{ml}$ in the untreated HC. In a similar fashion, the secretion of IL- 8 increased from $6.1 \mathrm{ng} / \mathrm{ml}$ (untreated $\mathrm{HC}$ ) to a concentration of $7.29 \mathrm{ng} / \mathrm{ml}(P<0.01)$ and $8.11 \mathrm{ng} / \mathrm{ml}(P<0.01)$ in the two concentrations of FFA treated HC (Fig. 4). For our positive control $\mathrm{H}_{2} \mathrm{O}_{2}$, the concentration of IL- 6 was $27.4 \mathrm{ng} / \mathrm{ml}(P<0.01)$, for IL-8, the concentration was $8.6 \mathrm{ng} / \mathrm{ml} P<0.01)$.

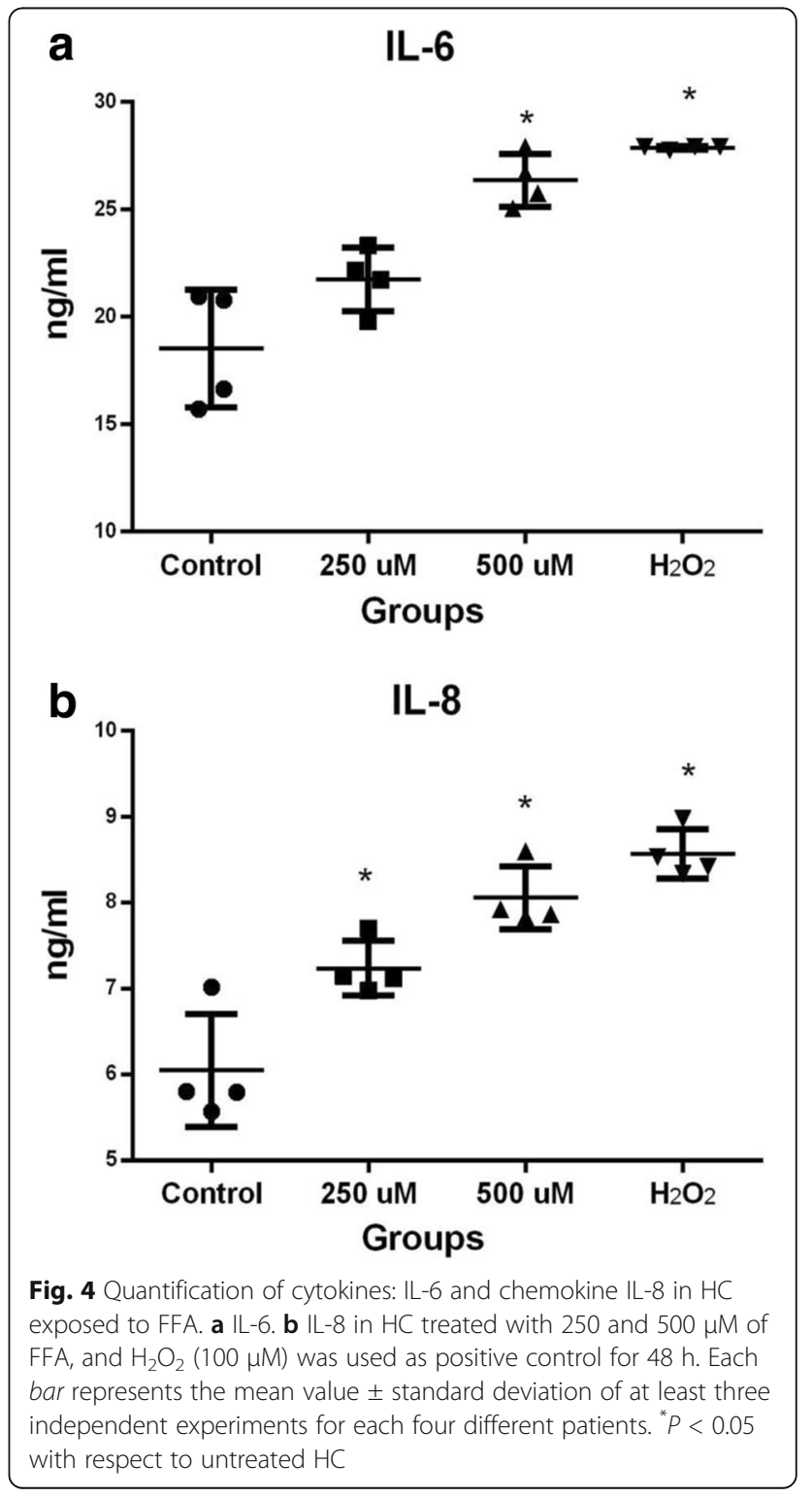


A statistically significant positive correlation was identified between $\mathrm{O}_{2}^{-}$intracellular production and IL-8 concentration (Fig. 5a) (rho $=0.93$; Bonferroni-adjusted $P$-value $=0.01)$. Although, there was a positive correlation between $\mathrm{NO}$ and $\mathrm{H}_{2} \mathrm{O}_{2}$ production and IL-8 concentration, the magnitude was not statistically significant (rho $=0.62, P=1.00$; and rho $=0.69, P=0.87$ ). None of the IL- 6 concentration and ROS production correlations were statistically significant, however, this data showed similar trend as IL-8 (Fig. 5b).

\section{Discussion}

In this study, we observed that a lipidic microenvironment in human chondrocytes induces oxidative stress and elicits a proinflammatory response, that could be reflected in joint diseases. Our results show that FFA stimulates the production of ROS and RNS such as $\mathrm{O}_{2}^{-}$, $\mathrm{H}_{2} \mathrm{O}_{2}$, and $\mathrm{NO}$, respectively, as well as the production of the cytokine IL- 6 and chemokine IL- 8 at the two FFA doses tested.

The role of ROS in the development of OA has been well documented. Henrotin et al. [15] showed that ROS promote chondrocyte apoptosis and inhibits matrix synthesis, therefore, promoting its breakdown [20]. In addition, several studies suggest that NO production is increased in chondrocytes from OA patients due to an overexpression of the inducible NO synthase (iNOS) causing chondrocyte apoptosis [21-23]. In an in vitro model, Sasaki et al. [24] found that NO has a deleterious effect in chondrocytes as it promotes the release of basic fibroblast growth factor (bFGF), which triggers the expression of metalloproteinases and iNOS. The NO could induce the production of cellular mediators that carry proteolytic properties on the extracellular matrix proteins such as fibronectin, type II collagen and hyaluronic acid [24]. The relevance of NO is highlighted by its signaling action, activating key signaling pathways in chondrocytes leading to in proteoglycan degradation, but also to the fact that it can induce the release of $\mathrm{O}_{2}^{-}$by a donor compound to form peroxynitrite, creating a deleterious state in the cartilage as described by Scher et al. [20].

In our $\mathrm{HC}$ in-vitro model, we observed that at $48 \mathrm{~h}$, the internalization of FFA by chondrocytes induces the production of ROS and RNS, suggesting that a hyperlipidemic microenvironment plays a key role in situ oxidative stress-state related to cartilage injury, characteristic in the OA development. In addition to the ROS

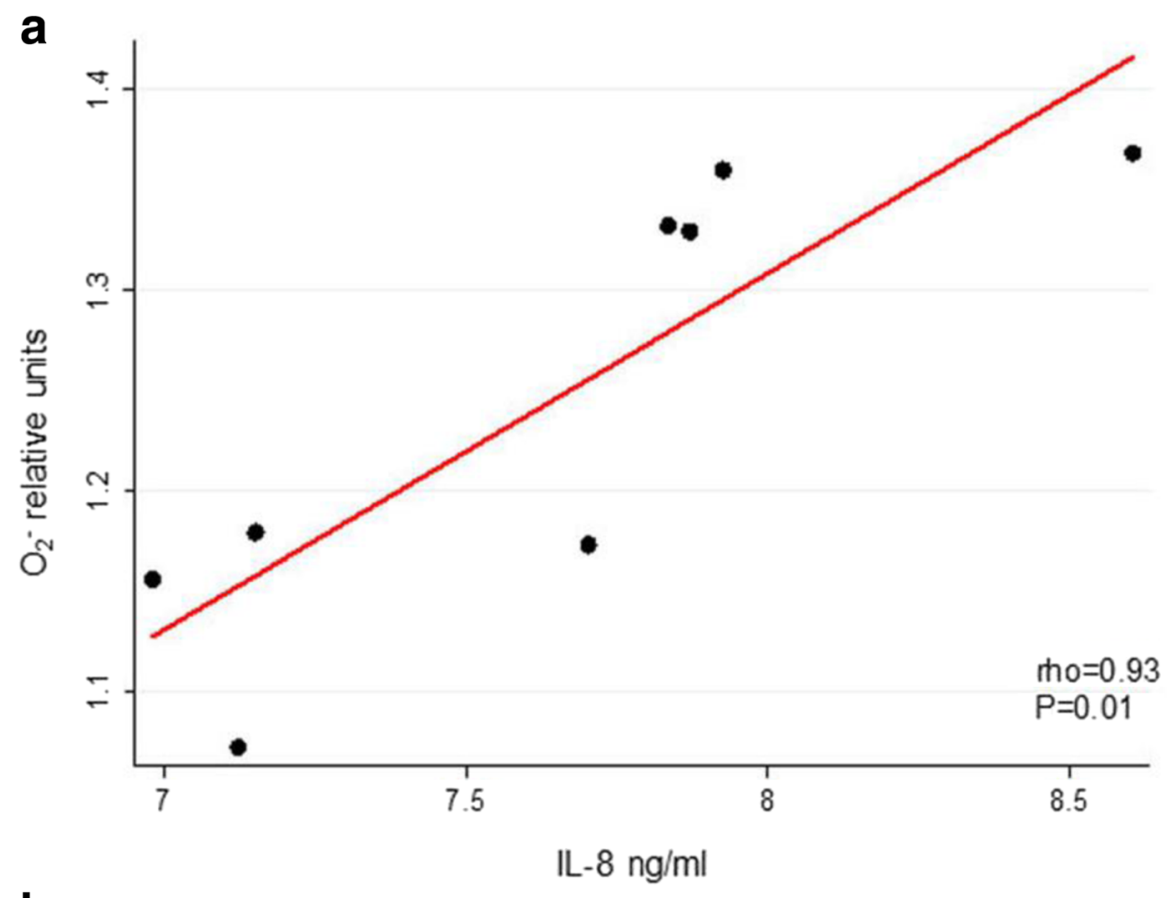

b

\begin{tabular}{|l|l|l|l|}
\hline \multirow{2}{*}{} & \multicolumn{3}{|c|}{ Spearman's rho (Bonferroni adjusted $P$-value) } \\
\cline { 2 - 4 } & $\mathrm{O}_{2}-$ & $\mathrm{ON}^{-}$ & $\mathrm{H}_{2} \mathrm{O}_{2}$ \\
\hline $\mathrm{IL}-8$ & $0.93(0.01)$ & $0.62(1.00)$ & $0.69(0.87)$ \\
\hline $\mathrm{IL}-6$ & $0.69(0.87)$ & $0.67(1.00)$ & $0.67(1.00)$ \\
\hline
\end{tabular}

Fig. 5 Statistical correlation between the results: a Positive correlation between $\mathrm{O}_{2}^{-}$intracellular production and IL-8 concentration. b Spearman correlation coefficients ROS production and IL-6 and IL-8 
production, we show evidence that $\mathrm{HC}$ stimulated with FFA leads to an increase on the cytokine IL- 6 and chemokine IL- 8 in an autocrine fashion. IL- 6 has been strongly associated with the development of $\mathrm{OA}$ as it acts as a mediator in the degeneration of the cartilage $[25,26]$; furthermore, high levels of IL-6 have been associated with an increased loss of tibial cartilage [27]. Our results strongly suggest that FFA works as an inductor of cartilage damaged driven by oxidative stress that enhances the production of pro-inflammatory cytokines leading to cartilage damage.

On the other hand, IL-8 chemokine has also been shown to have a deleterious effect in OA [28]. IL-8 functions as neutrophils chemoattract at the injury site; increasing the content of ROS and others mediators of cell damage [29]. Moreover, ROS can induce IL-8 production along other inflammatory mediators such as prostaglandins that could lead to further tissue damage [30].

We provide evidence that the increase oxidative stress caused by $\mathrm{HC}$ exposed to FFA leads to ROS and RNS production, autocrine activation of IL- 6 and IL- 8 by chondrocytes leading to cartilage damage. Our data suggest that the oxidative stress along with an inflammatory response triggers an imbalance in the cartilage homeostasis as seen in OA patients with obesity [30]. Taken together, our data suggest that hyaline cartilage intra-substance with increased fatty acids, could induce an inflammatory response mediated by IL-6, IL-8, and oxidative stress in which free radicals, mainly $\mathrm{NO}$, trigger the degeneration of the extracellular matrix. The highly lipidic

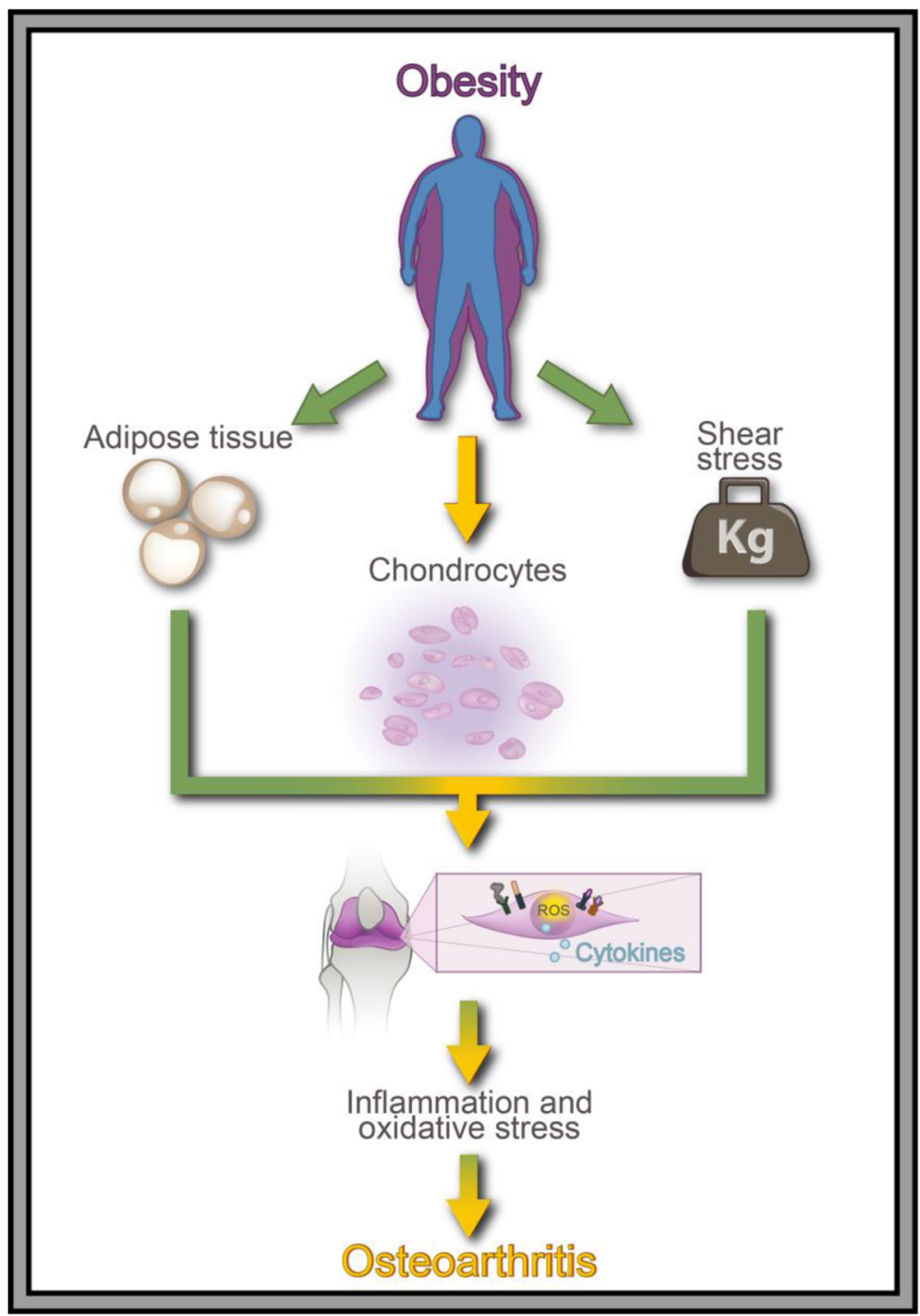

Fig. 6 Graphic representation of the role of obesity: On oxidative stress leading to cytokine and chemokine autocrine production in OA. In this figure, it is possible to appreciate that the relation between obesity and OA is more than biomechanical stress where an increase in lipid composition in the cartilage induces the formation of pro-inflammatory mediators, ROS and RNS leading to cartilage damage 
microenvironment causes a cartilage damage by not only and increase in IL-1 [31], but also by an increase in ROS and RNS that enhances the autocrine expression of the cytokine IL-6 and chemokine IL-8 respectively. Our results provide a novel mechanism of increase oxidative stress in cartilage injury by FFA.

\section{Conclusions}

In conclusion, this work suggests an alternative mechanism in which an increase in the lipid composition in the cartilage also contributes to the development of $\mathrm{OA}$ and may suggest why non-weight-bearing joints such as the small joints of the hand are affected in OA patients with obesity and dyslipidemia (Fig. 6). Although our results are robust, further studies to the specific effect of FFA over $\mathrm{HC}$ all of these to elucidate more clearly the relation between obesity and osteoarthritis, considering the complex interaction of genetic, metabolic and biomechanical factors.

\section{Abbreviations}

FFA: Free fatty acids; HC: Human chondrocytes; IL-6: Interleukin-6; IL8: Interleukin-8; OA: Osteoarthritis; RNS: Reactive nitrogen species; ROS: Reactive oxygen species

\section{Funding}

We declare there was not funding for the development of this research.

\section{Availability of data and materials}

This manuscript has availability of data and materials.

\section{Authors' contributions}

DML: Cell cultures, Oxidative stress experiments, pro-inflammatory molecules quantification, data acquisition, drafting of the article, critical revision of the manuscript. MGSO: Cell cultures, data acquisition, critical revision of the manuscript. YZC: Cell cultures, oxidative stress experiments and acquisition of data. KMF: Pro-inflammatory molecules quantification and acquisition of data. JFT: Data interpretation, critical revision of the manuscript. GAMN: Statistical analysis, data interpretation, critical revision of the manuscript. DCC: Data interpretation and critical revision of the manuscript. AOM: Provision of biopsies, collection of medical records and critical revision of the manuscript. LEGQ: Drafting of the article, critical revision of the manuscript. MCGR: Data interpretation of oxidative stress and critical revision of the manuscript. CP, CHD and FBJ: Diagnostic of patients and critical revision of the manuscript. AGLR: Conception of the study, drafting of the article, critical revision of the manuscript and data interpretation. All authors have approved the final version of the manuscript.

\section{Competing interests}

The authors declare that they have no competing interests.

\section{Consent for publication}

All figures are consent for publication.

\section{Ethics approval and consent to participate}

This protocol was approved and consenting by the research committee of the Instituto Nacional de Rehabilitación, under the reference number 08/11.

\section{Publisher's Note}

Springer Nature remains neutral with regard to jurisdictional claims in published maps and institutional affiliations.

\section{Author details}

'Synovial Fluid Laboratory, Instituto Nacional de Rehabilitación "Luis Guillermo Ibarra", Calzada México Xochimilco 289, 14389 Mexico City,
Mexico. ${ }^{2}$ Departamento de Ciencias de la Salud, Universidad Autónoma Metropolitana Iztapalapa, Avenida San Rafael Atlixco 186, Iztapalapa, 09340 Mexico City, Mexico. ${ }^{3}$ Musculoeskeletal and Articular Ultrasound Laboratory, Calzada Mexico-Xochimilco 289, Col. Arenal de Guadalupe, Tlalpan, 14389 Mexico D.F, Mexico. ${ }^{4}$ Arthroscopy Service; Instituto Nacional de Rehabilitación "Luis Guillermo Ibarra Ibarra", Secretaría de Salud, Calzada Mexico-Xochimilco 289, Col. Arenal de Guadalupe, Tlalpan, 14389 Mexico D.F. Mexico. ${ }^{5}$ Rheumatology Division, ProteoRed/ISC III Proteomics Group, INBIC, A Coruña, Spain. ${ }^{6}$ Division of Rheumatology, Warren Alpert School of Medicine at Brown University, Providence, RI, USA.

Received: 15 May 2017 Accepted: 1 June 2017

Published online: 12 June 2017

\section{References}

1. Contreras-Hernandez I, Mould-Quevedo JF, Torres-Gonzalez R, GoycocheaRobles MV, Pacheco-Dominguez RL, Sanchez-Garcia S. Cost-effectiveness analysis for joint pain treatment in patients with osteoarthritis treated at the Instituto Mexicano del Seguro Social (IMSS): comparison of nonsteroidal anti-inflammatory drugs (NSAIDs) vs. cyclooxygenase-2 selective inhibitors. Cost Eff Resour Alloc. 2008;6:21.

2. Haq I, Murphy E, Dacre J. Osteoarthritis. Postgrad Med J. 2003;79(933):377-83.

3. Woolf AD, Pfleger B. Burden of major musculoskeletal conditions. Bull World Health Organ. 2003;81(9):646-56.

4. Conde J, Scotece M, Gomez R, Lopez V, Gomez-Reino JJ, Gualillo O. Adipokines and osteoarthritis: novel molecules involved in the pathogenesis and progression of disease. Arthritis. 2011;2011:203901.

5. Josefsson E, Tarkowski A. Suppression of type II collagen-induced arthritis by the endogenous estrogen metabolite 2-methoxyestradiol. Arthritis Rheum. 1997:40(1):154-63.

6. Grotle M, Hagen KB, Natvig B, Dahl FA, Kvien TK. Obesity and osteoarthritis in knee, hip and/or hand: an epidemiological study in the general population with 10 years follow-up. BMC Musculoskelet Disord. 2008;9:132.

7. Jones G. What's new in osteoarthritis pathogenesis? Intern Med J. 2016; 46(2):229-36.

8. Oliveria SA, Felson DT, Cirillo PA, Reed JI, Walker AMM. Body weight, body mass index, and incident symptomatic osteoarthritis of the hand, hip, and knee. Epidemiology. 1999;10(2):161-6.

9. Hart DJ, Spector TD. The relationship of obesity, fat distribution and osteoarthritis in women in the general population: the Chingford study. J Rheumatol. 1993;20(2):331-5.

10. Pottie P, Presle N, Terlain B, Netter P, Mainard D, Berenbaum F. Obesity and osteoarthritis: more complex than predicted! Ann Rheum Dis. 2006;65(11):1403-5.

11. Conde J, Gomez R, Bianco G, Scotece M, Lear P, Dieguez C. Expanding the adipokine network in cartilage: identification and regulation of novel factors in human and murine chondrocytes. Ann Rheum Dis. 2011;70(3):551-9.

12. Hotamisligil GS, Shargill NS, Spiegelman BM. Adipose expression of tumor necrosis factor-alpha: direct role in obesity-linked insulin resistance. Science. 1993;259(5091):87-91.

13. Vuolteenaho K, Koskinen A, Kukkonen M, Nieminen R, Paivarinta U, Moilanen T. Leptin enhances synthesis of proinflammatory mediators in human osteoarthritic cartilage-mediator role of NO in leptin-induced PGE2, IL-6, and IL-8 production. Mediat Inflamm. 2009;2009:345838.

14. Beecher BR, Martin JA, Pedersen DR, Heiner AD, Buckwalter JA. Antioxidants block cyclic loading induced chondrocyte death. lowa Orthop J. 2007;27:1-8.

15. Henrotin YE, Bruckner P, Pujol JP. The role of reactive oxygen species in homeostasis and degradation of cartilage. Osteoarthr Cartil. 2003;11(10): $747-55$

16. Hutadilok N, Smith MM, Ghosh P. Effects of hydrogen peroxide on the metabolism of human rheumatoid and osteoarthritic synovial fibroblasts in vitro. Ann Rheum Dis. 1991;50(4):219-26.

17. Villalvilla A, Gomez R, Largo R, Herrero-Beaumont G. Lipid transport and metabolism in healthy and osteoarthritic cartilage. Int J Mol Sci. 2013;14(10): 20793-808.

18. Calamia V, Rocha B, Mateos J, Fernandez-Puente P, Ruiz-Romero C, Blanco FJ. Metabolic labeling of chondrocytes for the quantitative analysis of the interleukin-1-beta-mediated modulation of their intracellular and extracellular proteomes. J Proteome Res. 2011;10(8):3701-11.

19. Koopman R, Schaart G, Hesselink MK. Optimisation of oil red O staining permits combination with immunofluorescence and automated quantification of lipids. Histochem Cell Biol. 2001;116(1):63-8. 
20. Scher JU, Pillinger MH, Abramson SB. Nitric oxide synthases and osteoarthritis. Curr Rheumatol Rep. 2007;9(1):9-15.

21. Greisberg J, Bliss M, Terek R. The prevalence of nitric oxide in apoptotic chondrocytes of osteoarthritis. Osteoarthr Cartil. 2002;10(3):207-11.

22. Mazzetti I, Grigolo B, Pulsatelli L, Dolzani P, Silvestri T, Roseti L. Differential roles of nitric oxide and oxygen radicals in chondrocytes affected by osteoarthritis and rheumatoid arthritis. Clin Sci (Lond). 2001;101(6):593-9.

23. Tiku ML, Shah R, Allison GT. Evidence linking chondrocyte lipid peroxidation to cartilage matrix protein degradation. Possible role in cartilage aging and the pathogenesis of osteoarthritis. J Biol Chem. 2000;275(26):20069-76.

24. Sasaki K, Hattori T, Fujisawa T, Takahashi K, Inoue H, Takigawa M. Nitric oxide mediates interleukin-1-induced gene expression of matrix metalloproteinases and basic fibroblast growth factor in cultured rabbit articular chondrocytes. J Biochem. 1998;123(3):431-9.

25. Del Carlo M, Loeser RF. Nitric oxide-mediated chondrocyte cell death requires the generation of additional reactive oxygen species. Arthritis Rheum. 2002:46(2):394-403.

26. Wojdasiewicz P, Poniatowski LA, Szukiewicz D. The role of inflammatory and anti-inflammatory cytokines in the pathogenesis of osteoarthritis. Mediat Inflamm. 2014;2014:561459.

27. Stannus O, Jones G, Cicuttini F, Parameswaran V, Quinn S, Burgess J. Circulating levels of IL-6 and TNF-alpha are associated with knee radiographic osteoarthritis and knee cartilage loss in older adults. Osteoarthr Cartil. 2010;18(11):1441-7.

28. Finotti A, Borgatti M, Bezzerri V, Nicolis E, Lampronti I, Dechecchi M. Effects of decoy molecules targeting NF-kappaB transcription factors in cystic fibrosis IB3-1 cells: recruitment of NF-kappaB to the IL-8 gene promoter and transcription of the IL-8 gene. Artif DNA PNA XNA. 2012;3(2):97-296.

29. Davi G, Guagnano MT, Ciabattoni G, Basili S, Falco A, Marinopiccoli M. Platelet activation in obese women: role of inflammation and oxidant stress. JAMA. 2002;288(16):2008-14.

30. Chauffier K, Laiguillon MC, Bougault C, Gosset M, Priam S, Salvat C. Induction of the chemokine IL-8/Kc by the articular cartilage: possible influence on osteoarthritis. Joint Bone Spine. 2012;79(6):604-9.

31. Álvarez-García O, Rogers NH, Smith RG, Lotz MK. Palmitate has proapoptotic and proinflammatory effects on articular cartilage and synergizes with interleukin-1. Arthritis Rheumatol. 2014;66(7):1779-88.

\section{Submit your next manuscript to BioMed Central and we will help you at every step:}

- We accept pre-submission inquiries

- Our selector tool helps you to find the most relevant journal

- We provide round the clock customer support

- Convenient online submission

- Thorough peer review

- Inclusion in PubMed and all major indexing services

- Maximum visibility for your research

Submit your manuscript at www.biomedcentral.com/submit 